\title{
METODOLOGIA DE DESIGN: GANHOS DA ENGENHARIA PARA A SOLUÇÃO DE PROBLEMAS COMPLEXOS
}

\author{
Isabella Pontello Bahia \\ Mestranda, Universidade do Estado de Minas Gerais \\ isabellapont.bahia@gmail.com \\ Marielle Pereira Campos \\ Mestranda, Universidade do Estado de Minas Gerais \\ mariellecampos01@gmail.com
}

Resumo: O designer, enquanto solucionador de problemas é responsável por grande parte da entrega ao cliente por possuir uma metodologia abrangente; que combina métodos artísticos e científicos e vai além de apenas o desenvolvimento de um produto. Observa-se também que o método de design é semelhante e abarca elementos de outros métodos de projetação e verificação de soluções. Nota-se, entretanto, algumas teorias contemporâneas as quais alegam que a pesquisa acerca do método de design deve receber mais atenção a fim de que a prática seja mais coerente com os desafios complexos da atualidade. Dessa maneira, o estudo aqui apresentado busca sanar questionamentos acerca do método de projeto em design a fim de compreender quando e como ele é suficiente para sanar problemas complexos. Propõe-se, pois, aproximar a metodologia utilizada pelos designers para a solução de problemas com o método de Análise de Valor, oriundo da engenharia.

Palavras-chave: método, design, engenharia, análise de valor

\begin{abstract}
The designer, while troubles hooter is responsible for much of the delivery to the customer by having a comprehensive methodology; combining artistic and scientific methods and goes beyond just the development of a product. It is also noted that the design method is similar and includes elements ofo ther methods of projecting and verification solutions. It is perceived, however, some theories which claim that contemporary research about the design method should get more attention so that the practice is more consistent with the complex challenges of today. Thus, the study presented here seeks to remedy questions about the design method in design in order to understand when and how it is sufficient to solve complex problems. It is proposed, therefore, to approach the methodology used by the designers to solve problems with the method of Value Analysis, arising from engineering.
\end{abstract}

Keywords: method, design, engineering, valueanalysis 


\section{INTRODUÇÃO}

Imersos na ótica promissora do design como meio de combinar recursos e agentes a fim de obter-se singularidade projetual (na solução de problemas), nota-se, entretanto, uma ampla gama de significados diversos atrelados ao termo design. A diversidade, neste caso, só torna mais complexo o processo de compreensão da atividade, bem como possibilita percepções turvas de resultados obtidos pela ação projetual (CARDOSO, 2008). Por outro lado, é possível analisar diversos campos do conhecimento bastante estruturados e populares no âmbito geral de compreensão social - a engenharia e medicina, por exemplo.

Em análise sobre tal questão é possível compreender que o projetar em design possui métodos e ferramentas diversas (apesar de que contenham uma finalidade em comum). Elementos (métodos e ferramentas) estes que derivaram e/ou inspiram-se de outras áreas (BAXTER, 1998). Assim é possível compreender que, a falta de diálogo do design paracom a sociedade muito é graças á pouca visibilidade da atividade projetiva e não pelo questionamento aos métodos e ao projetar - o que nesta compreensão assemelham-se, em grande extensão do projeto às etapas de métodos das áreas já mencionadas e consideradas como ciências bem estruturadas (TEIXEIRA, 2011).

Se a singularidade do design reside nessa combinação de métodos artísticos e científicos em uma prática, mais estudos a respeito dessas permutações complexas podem ajudar a aprimorar a compreensão não só de como as formas de pensamento artístico são parte do design, mas de forma mais ampla, como elas contribuem para os processos de pesquisa e desenvolvimento (TEIXEIRA, p.23, 2011).

A partir de tal questionamento põe-se aqui em outro ângulo de visão, abordase, pois, a Análise de Valor (CSILLAG, 1995). A partir do recorte traçado no design, que compreende a visibilidade contemporânea e o grande potencial para resolução de problemas complexos, buscou-se, pois, um método capaz de ser comparado e associado com o método de design (BAXTER, 1998). Um método que, primeiramente traga questões pouco presentes no método de design - como a mensuração de resultados e a enumeração de indicadores - e que possua etapas extremamente rígidas e controladas - aqui a ideia de compreender as diferenças e balanceá-las.

O estudo em questão tem como temática a resolução de dois questionamentos. O primeiro refere-se a semelhança do método de design com outros métodos de projetação e verificação de soluções, cabe aqui compreender qual é essa semelhança. Já o segundo, que é uma interpretação do primeiro, abrange o entendimento de como esses métodos podem se aproximar a fim de, principalmente, resolverem os problemas complexos da atualidade.

Ainda nesta linha de pensamento pretende-se, pois, compreender a estruturação e o funcionamento do método de design a fim de justificar sua atuação para a resolução de problemas complexos. Para isso, pretende-se aproximar a metodologia utilizada pelos designers para a solução de problemas com o método de Análise de Valor, oriundo da engenharia. Dessa forma, objetiva-se especificamente explicar a metodologia utilizada pelos designers no desenvolvimento de soluções bem como o método Análise de Valor, além de identificarsituações em que é importante a convergência dos métodos (complexidade, cenários prospectivos, visão de futuro). Por 
fim, e não menos importante, realizar a convergência dos mesmos através de um instrumento inspirado no modelo $5 \mathrm{~W}_{2} \mathrm{H}^{1}$ (LISBOA e GODOY, 2012).

\section{DESENVOLVIMENTO}

\subsection{Complexidade e problemas da atualidade}

Desenvolver produtos que atendam as necessidades dos usuários. Essa foi e, em muitos casos ainda é, a atribuição do designer. Entretanto, ao inseri-lo em realidades e situações complexas, observa-se que, mais do que um projetista que segue demandas sugeridas, o designer é um solucionador de problemas (BURDECK, 2006). Nota-se, pois, que enquanto imersos em uma realidade globalizada na qual cultura, sociedade, economia e negócios possuem necessidades distintas, tem-se a ascensão do designer - profissional - como articulador de ideias e o design - atividade - um meio de visualizar holisticamente os problemas da atualidade (CARDOSO, 2012).

Ainda que, muito ligado à ideia do projeto e à concepção de um produto questão que limita a denominação da atividade, em seus primórdios, como desenho industrial ${ }^{2}$ - já é possível compreender (e classificar) o design como ciência (BONSIEPE, 2011). Ou seja, como atividade que conecta complexidades temáticas, estéticas e metodológicas e que também desenvolve soluções (aqui se vê o designer como profissional solucionador de problemas e não apenas desenvolvedor de projetos) em áreas diversas.

Tem-se, pois, o design hoje, que em contrapartida à ideia inicial ligada apenas à aparência, passou a ser uma ferramenta de atuação na complexidade. $O$ design hoje se constitui com mais uma habilidade, a de gerir sistemas complexos; "o designer produzindo para as pessoas, ou seja, o primeiro sistema complexo produzindo para o segundo" (LANA, p. 59, 2011).

A teoria dos problemas capciosos, wicked problems, (RITTEL e WEBBER, 1973), aborda a fundo esta questão. São definidos por wicked problems todas aquelas demandas de complexa compreensão e, em primeira instância sem solução precisa. Também são compreendidos por problemas únicos e de alto nível, que não possuem soluções verdadeiras ou falsas, mas aplicáveis ou inaplicáveis. São questões integralmente sociais que por sua atuação transversal e, pois, interdependente, envolvem vários atores e possibilidades. Apesar da formulação da teoria datar os anos de 1960, ela ganha força na contemporaneidade - principalmente ao ser associada com os efeitos da globalização e da massificação do pensamento e a diminuição das fronteiras.

A associação dessa teoria ao design thinking (BUCHANAN, 1992) também é relevante e, para o estudo em questão fundamental, pois compreende a necessidade da articulação de atores de áreas diversas no processo e, pois, de metodologias. Tal associação defende a questão de que tal como os problemas capciosos o design

${ }^{1}$ 5W2H é uma ferramenta de gestão relacionada à Análise da Cadeia de Valor. Funciona como um mapeamento das atividades e tem como objetivo eliminar por completo qualquer dúvida que possa surgir sobre um processo e/ou atividade.

${ }^{2}$ Desenho industrial é uma das primeiras denominações da atividade hoje compreendida como Design. Esta denominação era empregada, pois o profissional, em sua grande maioria, desenvolvia produtos para a indústria (CARDOSO, 2005). 
thinking atua em um escopo universal; é aplicado em qualquer tipo de experiência e/ou vivência humana e, pois, em toda a complexidade.

A metodologia em design, portanto, é a força motriz da condução desta mudança de atuação do design; "sem o método, o que resulta não é design, mas o acaso, que não permite valoração quantitativa e ou qualitativa, repetição ou aprimoramento" (LANA, p. 60, 2011). Compreendê-la e aperfeiçoá-la é, pois, uma tarefa extremamente relevante e necessária para os projetistas contemporâneos.

\subsection{Introdução à Análise de Valor}

A terminologia "Valor" compreende uma gama de atribuições e significados que perpassam várias áreas do conhecimento - filosofia, engenharia, marketing, entre outras (CSILLAG, 1995). Na esmagadora maioria das áreas, entretanto, é possível observar que o termo valor trata-se de um conceito crucial nas relações sociais, políticas e econômicas, pois é o que permite equiparar dois produtos - serviços, distintos sob um denominador comum (SCHÄFER, 2011).

Também conhecida como Engenharia do Valor, a Análise de Valor é um conjunto de ferramentas estruturadas que propõe aperfeiçoar produtos, serviços e atividades enquanto sistema, através de uma visualização holística e ativa das etapas do processo em questão (CSILLAG, 1995). Inicialmente era aplicada apenas em ativos em andamento, porém hoje já é possível inseri-la em processos em construção, ainda que em fase de ideação.

O interesse sobre Análise de Valor aumentou na década de cinquenta nos EUA e foram feitas tentativas de aplicá-la para produtos complexos, assim como para processos de manufatura, serviços e trabalhos administrativos, o que se conseguiu ao longo do tempo com o uso de técnicas que foram sendo emprestadas de outras áreas do conhecimento, como a psicologia, de técnicas especiais desenvolvidas conforme a necessidade, como as de abordagem funcional (CSILLAG, p. 26, 1995).

O método tem como objetivo a melhoria do item analisado a partir de dois pontos de vista; o custo e o valor. O primeiro item, custo, é trabalhado no sentido da redução monetária de investimento sobre o ativo. Ou seja, o método propõe a compreensão da formação de custos do produto analisado para, em sequência, gerar soluções criativas que possibilitem a maior redução possível desse custo. É interessante, pois, previamente ao desenvolvimento de uma solução existe um diagnóstico em cima da situação atual. E é esse diagnóstico que possibilita a criação de indicadores de melhoria tendo como base a proposta de solução.

O segundo item, valor, é de certa forma mais complexo que o primeiro. No método Análise de Valor, o valor é expresso em relação a algo, portanto, é traçado por meio de comparação e, desconsiderando as sete classes de valor descritas por Aristóteles ${ }^{3}$, é medido apenas em termos monetários. Concentrando-se no que diz

\footnotetext{
${ }^{3}$ A teoria Aristotélica aponta a existência de sete classes de valor: econômico, político, social, estético, ético, religioso e judicial (ARISTÓTELES, 1985). O estudo em questão aborda os valores econômicos.
} 
respeito ao método, definem-se quatro tipos de valores econômicos: Valor de custo; valor de uso; valor de estima e valor de troca.

. Valor de custo, como sendo o total de recursos medido em dinheiro, necessário para produzir/obter um item.

- Valor de Uso, como a medida monetária das propriedades ou qualidades que possibilitam o desempenho de uso, trabalho ou serviço.

- Valor de Estima, como a medida monetária das propriedades, características ou atratividades que tornam desejável sua posse.

- Valor de Troca, como a medida monetária das propriedades ou qualidades de um item que possibilitam sua troca por outras coisas (CSILLAG, p. 61, 1995).

Para tal abordagem, mais uma vez, é usada a ferramenta do diagnóstico e o valor em análise "é sempre uma entidade relativa e correspondente à combinação de tipos específicos de valores. Em geral, aumenta com maiores valores de uso e de estima e diminui com o crescimento do valor de custo" (CSILLAG, p.62,1995).

As etapas do método são bem definidas através do plano de trabalho (ver quadro 1) nos quais são inseridas descrições detalhadas de todos os processos analisados, além de demais elementos que possam estar envolvidos - ex: gestão, fator humano, produtos, etc. $O$ plano possui sete fases: 1. Fase de orientação; 2. Fase de Informação; 3. Fase Criativa; 4. Fase de Análise; 5. Fase de planejamento do programa; 6. Fase de execução do programa e 7. Fase de resumo e conclusões.

Quadro 1 - Etapas da Análise de Valor.

\begin{tabular}{|l|l|l|}
\hline $\mathbf{1}$ & Fase de Orientação & Diagnóstico e demandas \\
\hline $\mathbf{2}$ & Fase de Informação & Pesquisa \\
\hline $\mathbf{3}$ & Fase Criativa & Geração de alternativas \\
\hline $\mathbf{4}$ & Fase de Análise & Quantificação e prioridades \\
\hline $\mathbf{5}$ & Fase de Planejamento & Programação do trabalho \\
\hline $\mathbf{6}$ & Fase de Execução & Especificações \\
\hline $\mathbf{7}$ & Fase de Conclusões & Plano de Trabalho \\
\hline
\end{tabular}

Fonte: Elaborado pelas autoras, com base na pesquisa realizada (2015) e Csillag (1995).

O método Análise de Valor consiste, pois, em uma rica e estruturada possibilidade de trabalho para sanar questões ora complexas, ora não ordenadas, pois visa principalmente à organização e a compreensão do todo a fim de desenvolver soluções que gerem resultados comprovados e positivos.

Na sequência vê-se necessário compreender o método de design a fim de identificar suas características, bem como, seus resultados. A proposta de conectá-los vem em série. 


\subsection{Método de Design}

O método de design é conhecido por combinar técnicas científicas e artísticas em prol da resolução de um problema envolvendo, ou não, o desenvolvimento de um produto palpável (MOZOTA, 2011). Questiona-se, entretanto, a divisão das etapas bem como o engessamento do processo ao argumentar que, na prática, não é comum o uso de técnicas cartesianas e sequências lineares (VIANNA, 2012). Muitos são aqueles que defendem a aleatoriedade do método. Entretanto, vamos aqui identificar o processo e as etapas sem engessá-los, apenas compreendendo o lugar no todo e, assim, problematizar como isso pode ser melhor aproveitado. A referência de método em design é, pois, difusa (mesmo que possua a mesma ideologia), entretanto vamos aqui apresentar duas propostas tendo uma como caso a ser aprofundado.

Primeiramente observa-se o Design Thinking, o qual propõe uma abordagem que utiliza sensibilidade, ferramentas de criatividade e trabalho interdisciplinar em grupo para resolver problemas e atender às necessidades das pessoas através da seleção de alternativas viáveis e comercialmente factíveis (BROWN, 2009).

O Design Thinking, enquanto bibliografia, trás uma questão extremamente relevante que é a inovação. A proposta está extremamente conectada com a possibilidade de visualizar novos horizontes, produtos e serviços e como eles podem ser desenvolvidos. Entretanto, também nota-se uma pequena (ou nenhuma) preocupação com indicadores e com o entendimento do cenário prévio a fim demedir as soluções em cenários futuros. Neste âmbito uma questão se torna frequente (social e economicamente); quanto o design thinking funciona?

As etapas do método consistem em três: 1. Imersão; 2. Ideação e 3. Prototipação, que apesar de organizados sequencialmente nem sempre obedecem tal cronologia, e são frequentemente completadas com demais etapas ou sub ações, bem como em um ciclo, identificando a conexão e interdependência entre as etapas.

No mais, como o próprio nome já diz, o Design Thinking se refere à maneira do designer de pensar, que utiliza um tipo de raciocínio pouco convencional no meio empresarial, o pensamento abdutivo. Nesse tipo de pensamento, busca-se formular questionamentos através da apreensão ou compreensão dos fenômenos, ou seja, são formuladas perguntas a serem respondidas a partir das informações coletadas durante a observação (VIANNA, p. 13, 2012).

Em outra concepção (BURDEK, 2006), o processo de design pode ser entendido como um sistema de manipulação de informações. É caracterizado por várias possibilidades de realimentação (feedback, ou seja, a possibilidade de revisão da etapa que se acabou de realizar), o que comprova que o processo metodológico de design não é um simples processo linear de resolução de problemas, conforme apresentado no esquema da Figura 1. 


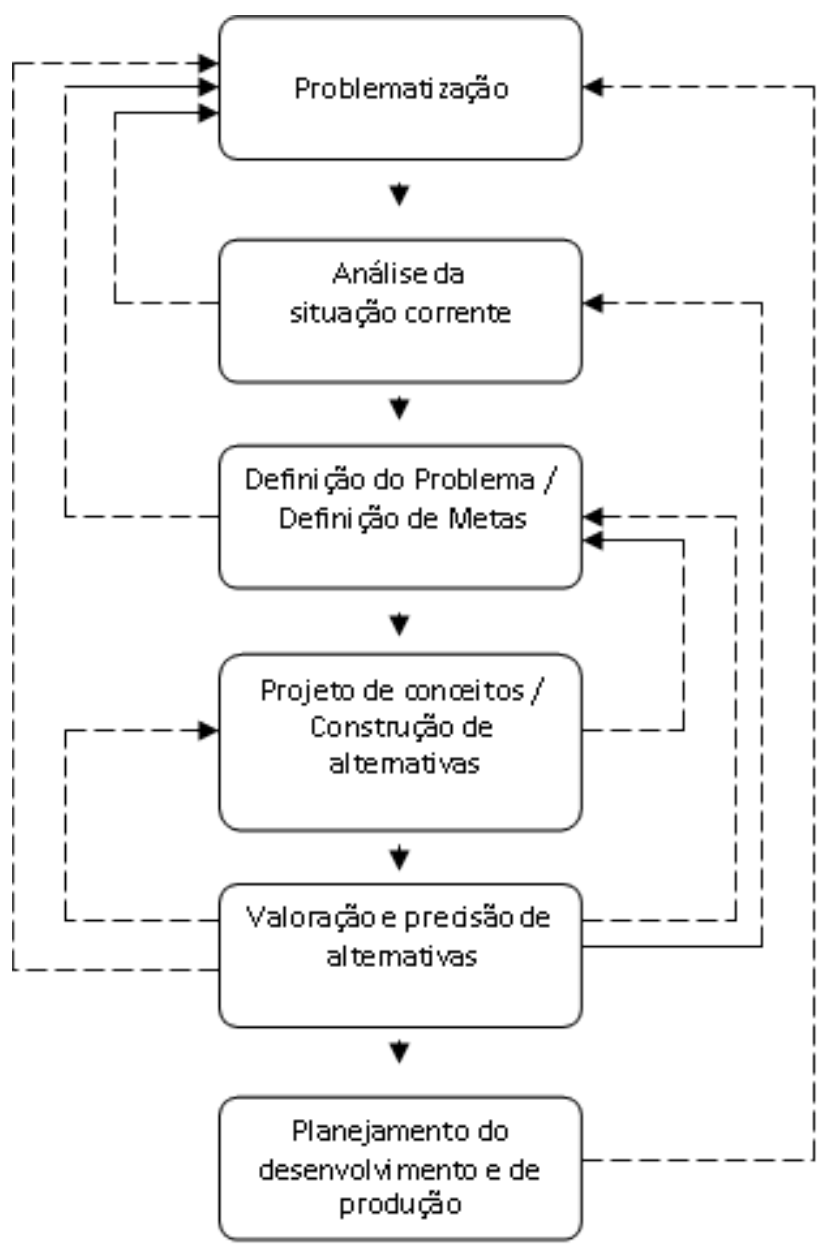

Figura 1- Método do Processo de Design.

Fonte: Burdeck (2006)

No que diz respeito à identificação de problemas, correspondente às primeiras etapas, (fases de problematização; análise da situação corrente; Definição do Problema/Definição de metas) uma ferramenta do design muito útil às empresas é o briefing, que, através de alguns de seus elementos se destina a levantar e expor de forma clara e objetiva os problemas da organização e o planejamento estratégico do negócio, fazendo a intermediação planejada entre a demanda e a ação, em busca de inovações e melhorias das organizações (PHILLIPS, 2007). Assim o briefing constitui-se uma importante ferramenta para a compreensão de cenários e contextos. Seu uso também é importante para elaborar um cronograma com prazos para cada etapa, além de permitir o acompanhamento da evolução das etapas do projeto e verificar se os resultados previstos foram realmente atingidos - qualitativamente.

O briefing da inovação ${ }^{4}$ contém a descrição de um projeto envolvendo uma atividade inovadora ou mesmo estratégica. É um roteiro a ser seguido durante o desenvolvimento de um projeto e deve conter o que fazer (problema a resolver), como fazer (o planejamento das etapas a serem seguidas), por que fazer e quais são os

\footnotetext{
${ }^{4}$ Briefing da Inovação termo visto com frequência na Europa voltado a atividades inovadoras e estratégicas. Trata-se de uma denominação equivalente a "briefing criativo", "briefing do projeto", "especificação do projeto" e "descrição da tarefa". (PHILLIPS, 2007)
} 
resultados a serem alcançados. Para responder a essas perguntas é necessário seguir as seguintes etapas: definição clara dos objetivos do projeto, sua natureza e contexto; análise do público-alvo; análise da coerência entre os objetivos do negócio e as estratégias para alcançá-los; análise setorial: estratégia da empresa (preço, qualidade, apelo ecológico, exclusividade), análise de concorrentes e estudo de tendências do mercado. Além disso, o briefing aborda pontos como requisitos técnicos (recursos disponíveis de produção, distribuição e divulgação disponíveis na empresa), prazo e orçamento para a realização do projeto.

$\mathrm{Na}$ busca de soluções (fase de projeto de conceitos/construção de alternativas) o objetivo é a geração de ideias através de técnicas de criatividade. No processo de design são utilizadas algumas ferramentas que podem ser facilmente transportadas para a construção de alternativas para a resolução dos problemas empresariais. Baxter (1998) apresenta algumas delas como brainstorming (tempestade cerebral), sinética (que se baseia em analogias e propõe a associação entre elementos diferentes aparentemente não relacionados entre si); análise paramétrica (serve para comparar produtos e estratégias em desenvolvimento com aquelas já existentes e adotadas por concorrentes, baseando-se em certas variáveis, chamadas de parâmetros comparativos) e análise do problema (para conhecer suas causas básicas e fixar suas metas e fronteiras, revelando os verdadeiros objetivos da empresa).

Refinar as soluções (fase de valoração e precisão de alternativas) significa identificar aquela que melhor se adéqua ao alcance do objetivo traçado. Para isso, as empresas encontram a sua disposição duas ferramentas: a votação; em que cada participante recebe 5 fichas e pode distribuí-las como quiser entre as ideias geradas, podendo, inclusive, colocá-las sobre uma única ideia; e a matriz de avaliação; em que as alternativas são colocadas nas colunas e os critérios de avaliação são colocados nas linhas da matriz, então notas (de um a dez) são dadas fazendo-se associações entre as linhas e colunas da matriz (BAXTER, 1998). O funil de decisões também pode se mostrar importante para tomar decisões em relação ás alternativas para inovar e ainda visualizar as variações do risco e incerteza ao longo do desenvolvimento do projeto: os retângulos em cinza claro representam as alternativas possíveis, e os retângulos brancos representam as decisões, durante a seleção de alternativas (Figura 2).

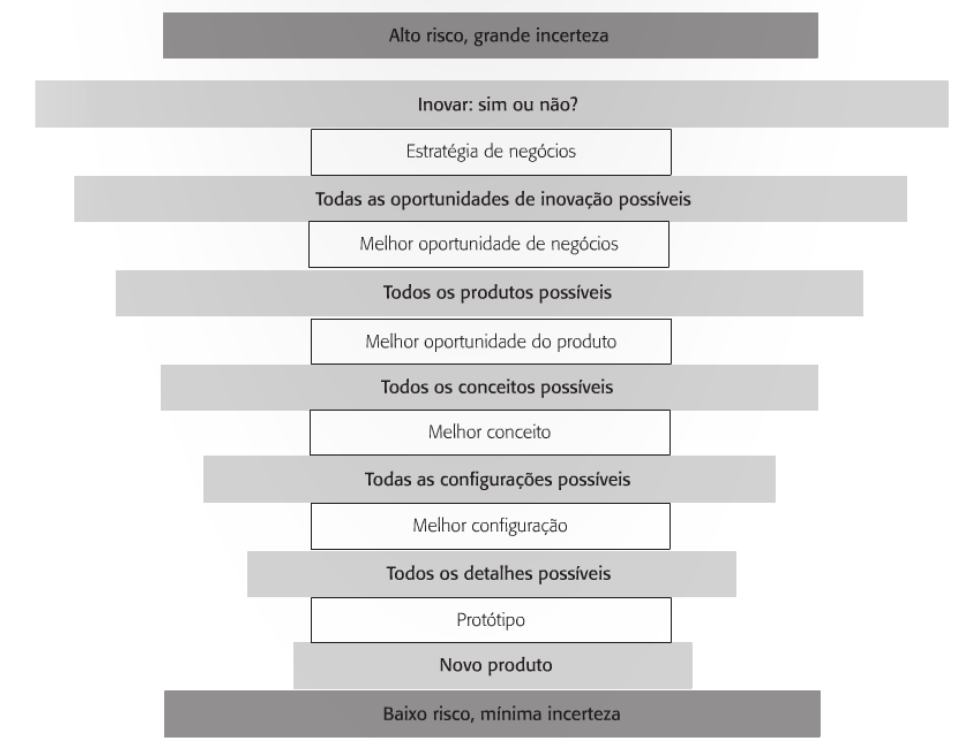

Figura 2 - Funil de decisões. Fonte: (BAXTER, 2011) 
O teste das soluções (fase de planejamento e desenvolvimento de produção) envolve a simulação de como o novo produto, novo serviço, novo processo ou nova ideia funcionará na prática antes que seja lançada no mercado. Serve também para verificar se a solução desenvolvida atende aos objetivos propostos no início do projeto. De certa forma, o método tende a formar um ciclo e as etapas, apesar de definidas, se misturam e coexistem ao longo do processo.

Em outras palavras, os métodos de design privilegiam a inovação, sempre tendo como foco centrar-se no usuário e a utilização de abordagens práticas, flexíveis e criativas para encontrar as melhores ideias e soluções finais.

\subsection{Compatibilização dos métodos}

Existem entre os dois métodos analisados muitas divergências. Partindo, primeiramente, do foco estipulado, em que para a análise de valor abarca em uma grande maioria dos casos apenas negócios e para o método de design é uma questão mais genérica - apesar de que no mercado é visível uma grande demanda por produtos. Outra questão observada é em relação à flexibilidade/rigidez dos métodos. Enquanto o design atua de uma forma flexível com etapas que coexistem o método da engenharia é rígido e uma etapa só é iniciada quando a anterior finaliza. Observa-se, ainda, o nível de análise; em design os resultados e as informações obtidas são preferencialmente qualitativas, já na análise de valor, preferencialmente quantitativas - questão que pode justificar a exatidão e a precificação de um método em detrimento ao outro (têm-se aqui a visão de um consumidor).

Entretanto, observa-se que nos dois métodos é possível visualizar inúmeros elementos em comum e mais, complementares. Segundo Lisboa e Godoy (2012), a técnica $5 \mathrm{~W} 2 \mathrm{H}$ permite identificar os dados e rotinas mais importantes de um projeto, quais os envolvidos, o que fazem e porque fazem. Ele é constituído de sete perguntas demostradas noQuadro2, que aplica a ferramenta 5W2H conforme Lisboa e Godoy (2012), para facilitar a compreensão dos métodos e, principalmente, para externalizar as características semelhantes e as possibilidades de conexões entre eles.

Quadro2 - Aproximação dos métodos a partir da aplicação do 5W2H

\begin{tabular}{|c|c|c|}
\hline & MÉTODO DE DESIGN & ANÁLISE DE VALOR \\
\hline 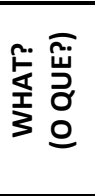 & $\begin{array}{l}\text { É um conjunto de operações necessárias, } \\
\text { dispostas em ordem lógica, que nos leva de } \\
\text { forma confiável e segura à solução de um } \\
\text { problema (MUNARI, 2000). }\end{array}$ & $\begin{array}{l}\text { É a aplicação consciente de um conjunto de } \\
\text { técnicas, que identificam funções } \\
\text { necessárias, estabelecem valores para as } \\
\text { mesmas e desenvolvem alternativas para } \\
\text { desempenhá-las ao mínimo custo. }\end{array}$ \\
\hline 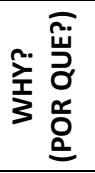 & $\begin{array}{l}\text { Atingir o melhor resultado com o menor } \\
\text { esforço. Inovação. }\end{array}$ & $\begin{array}{l}\text { Reduzir custos de produção de bens e } \\
\text { serviços e aumentar o valor para o usuário. }\end{array}$ \\
\hline 울 & $\begin{array}{l}\text { Designers e Não designers que utilizam o } \\
\text { design thinking. }\end{array}$ & $\begin{array}{l}\text { A metodologia utiliza o pessoal de } \\
\text { mercadologia para definir os requisitos do } \\
\text { cliente, engenharia para definir o produto e } \\
\text { manufatura para definir o processo de } \\
\text { produção conforme metas. Outros } \\
\text { especialistas contribuem, como os da área } \\
\text { de compras, de finanças, de qualidade, etc. }\end{array}$ \\
\hline
\end{tabular}




\begin{tabular}{|c|c|c|}
\hline 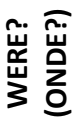 & $\begin{array}{l}\text { Qualquer campo de atividade; } \\
\text { Gráfico, produto, ambientes, moda e } \\
\text { serviços. }\end{array}$ & $\begin{array}{l}\text { Qualquer campo de atividade. Foco em } \\
\text { produtos novos, processos, serviços, } \\
\text { construção civil, energia, etc. }\end{array}$ \\
\hline 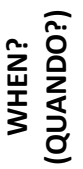 & $\begin{array}{l}\text { Sempre que houver um problema a ser } \\
\text { resolvido. }\end{array}$ & $\begin{array}{l}\text { Quando ocorrem grandes problemas } \\
\text { gerenciais. }\end{array}$ \\
\hline 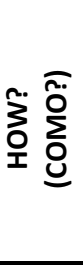 & $\begin{array}{l}\text { 1. Compreensão e definição do problema; } \\
\text { 2. Coleta de informações; } \\
\text { 3. Análise das informações encontradas; } \\
\text { 4. Desenvolvimento de alternativas; } \\
\text { 5. Avaliação de alternativas; } \\
\text { 6. Teste e experimentação. }\end{array}$ & $\begin{array}{l}\text { Análise do que realmente está } \\
\text { acontecendo e não do que se pensa estar } \\
\text { passando. Identificar as funções de } \\
\text { determinado produto, avaliá-las e propor } \\
\text { alternativas para desempenhá-las de } \\
\text { maneira mais conveniente. Planos de } \\
\text { trabalho. }\end{array}$ \\
\hline 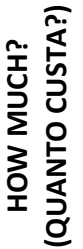 & Precificação extremamente diversificada. & Atividade onerosa. \\
\hline
\end{tabular}

Fonte: Elaborado pelas autoras, com base na pesquisa realizada, 2016.

\section{CONCLUSÃO}

O designer enquanto projetista de soluções é responsável por grande parte da entrega ao cliente graças à utilização de uma metodologia abrangente - que vai além de apenas o desenvolvimento de uma solução projetual. Entende-se que o designer abarca também uma função social, uma resposta ao problema que inclui muito mais que apenas a entrega de um projeto. Função esta que é extremamente requerida para os problemas da atualidade, para a complexidade. Neste quesito é possível observar, entretanto, que o método de design não possui ferramentas que consigam mensurar esta entrega e, pois, cria um ruído de comunicação social. O designer atua intensamente nos problemas através do desenvolvimento de soluções, entretanto não é capaz de demonstrar o quanto contribui para tal.

A associação do método de design com outros métodos é, pois, uma solução possível para a quebra deste tipo de ruído. Assim, o método de design torna-se suficiente para sanar problemas complexos quando conectado com métodos da engenharia, especificamente com a Análise de Valor.

O estudo em questão representa, portanto, não só uma iniciativa de levantar questionamentos e discussões a respeito do tema, mas também de ser um prelúdio para futuras pesquisas que venham a se aglutinar a esta e se aprofundar no assunto no que diz respeito à metodologia do design em instâncias mais profundas. 


\section{REFERÊNCIAS}

ARISTÓTELES. 1985. Ética a Nicômacos. Tradução de Mário Gama Kury. Brasília, Ed. UnB.

BAXTER, Mike. Projeto de Produto: guia prático para o design de novos produtos. Tradução: Itirolida. 2 ed. rev. São Paulo: Edgard Blücher,1998. 260p

Mike. Projeto de produto: guia prático para desenvolvimento de novos produtos. 3. ed. rev. São Paulo: Edgard Blücher, 2011.

BONSIEPE, Gui. Design, Cultura e Sociedade. São Paulo, Blucher, 2011.

BROWN, Tim. Design thinking: uma metodologia poderosa para decretar o fim das velhas ideias. Rio de Janeiro: Elsevier, 2010.

BUCHANAN, Richard. WickedProblems in Design Thinking. Design Issues 8, no. 2, 1992.

BURDEK, Bernhard E. Design: História, Teoria e Prática do Design de Produtos.

SãoPaulo: Blucher, 2006.

CARDOSO, Rafael. Design para um mundo complexo. Cosac Naify, 2012.

. 0 design Brasileiro antes do design: aspectos da história gráfica. São Paulo:

Cosacnaify, 2005.

CSILLAG, João Mário. Análise do valor: metodologia do valor, engenharia do valor, gerenciamento do valor, redução de custos, racionalização administrativa. São Paulo: Atlas, 1995.

LANA, Sebastiana Bragança. A complexidade dos métodos em design. Cadernos de Estudo Avançado em Design: Método. Barbacena, 2011.

LISBOA, Maria da Graça; GODOY, Leone Pentiado. Aplicação do método 5W2H noprocesso produtivo do produto: a joia. IberoamericanJournalof Industrial Engineering,Florianópolis, SC, Brasil, v. 4, n. 7, p. 32-47, 2012.

MOZOTA, Brigite Borja de. Gestão do design: usando o design para construir valor de marca e inovação corporativa. Porto Alegre: Bookman, 2011.

MUNARI, Bruno. Das coisas nascem coisas. São Paulo: Martins Fontes,2000

PHILLIPS, Peter L. Briefing: a gestão do projeto de design. Tradução: Itirolida. São Paulo: Editora Blücher, 2007. 183p.

RITTEL, Horst W. J; WEBBER, Melvin M. Dilemmas in a General Theoryof

Planning.PolicySciences Vol.4, N. 2, p: 155-16, 1973.

SCHÄFER, Márcio Egídio. Aristóteles e Marx: a propósito da determinação do valor. Controvérsia - Vol. 7, no 1: 07-17, 2011.

TEIXEIRA, Carlos. Prática reflexiva revisada. Cadernos de Estudo Avançado em Design: Método. Barbacena, 2011.

VIANA, Maurícioet al. Design thinking: inovaçãoemnegócio. Rio de Janeiro : MJV Press, 2012. 